\title{
Medical Care and Deaths due to Coronary Artery Disease in Brazil, 1980-1999
}

\author{
Ines Lessa
}

Salvador, BA - Brazil

\begin{abstract}
Objective - To estimate the frequency of medical care preceding deaths due to coronary artery diseases (CAD) in different Brazilian regions and capitals and to describe trends in medical care from 1980 to 1999.
\end{abstract}

Methods - Information on medical care preceding deaths due to coronary artery diseases/acute myocardial infarction in adults $\geq 20$ years from 1980 to 1999 was collected in the DATASUS, the databank of the Brazilian Health Ministry. Sex, states, and capitals selected for 1999 were analyzed in the study. Medical care was stratified as follows: with, without, and ignored medical care. The descriptive analysis comprised frequencies, ratios of frequency, test for proportions, and increments or reductions in frequencies.

Results - Acute myocardial infarction (AMI) represented 75 to $85 \%$ of the CAD in the period; the frequency of deaths with medical care ranged from 48.9 to $63 \%$, and that of ignored medical care ranged from 27.2 to $41.5 \%$. The frequency of other $C A D$ with medical care ranged from 56 to $76 \%$. The frequency of deaths preceded by medical care decreased by $17.8 \%$, and that with ignored medical care increased by $36.5 \%(R F=2)$. The values for the other $C A D$ were $-20.2 \%$ and $+64.6 \%(R F=44.4)$. Deaths preceded by medical care were more frequent in females at all ages and in all Brazilian regions.

Conclusion - The results show a high frequency of sudden death and suggest errors in diagnosis or codification and overestimation of the statistics about mortality. Validation of the death certificate diagnosis and frequent surveillance are required.

Keywords: medical care, deaths, coronary artery disease

Instituto de Saúde Coletiva, Universidade Federal da Bahia Mailing address: Ines Lessa - Rua Padre Feijó, 29/4 andar Cep 40110-170 - Salvador, BA, Brazil - E-mail: ines@ufba.br English version by Stela Maris C. e Gandour
Coronary artery disease, in particular acute myocardial infarction, is the major cause of sudden death ${ }^{1-8}$. However, studies on the validation of diagnoses are unanimous that an excessive number of unconfirmed acute myocardial infarctions occur, which results in overestimation of the statistics about mortality due to coronary artery disease ${ }^{4,69-16}$. Autopsy studies have shown a wide diversity in the diagnosis of sudden death varying with age and $\operatorname{sex}^{3,17-20}$. Other cardiac causes, including anomalies of the anatomic structure of the heart and coronary arteries with no atherosclerotic involvement, are common in sudden death under the age of 35 years ${ }^{3,13,16,18,20}$. On autopsy, the coronary arteries may show no involvement, sudden death being attributed to vasomotor phenomena or arrhythmias, or may show thrombosis but no evidence of erosion, plaque rupture, or acute lesions ${ }^{19-23}$.

Currently, coronary artery disease is the second cardiovascular cause of death in Brazil, but the first in São Paulo, both in the state and in the capital, and in some other capitals. In the last few years, coronary artery disease has shown a relative increase in both sexes, or only in the male sex. This may be partly due to the artifactual decrease in cerebrovascular diseases observed in the most recent statistics of mortality, and, although cerebrovascular diseases are also a cause of sudden death, deaths due to cerebrovascular diseases without medical care are less frequent than those due to coronary artery disease ${ }^{24}$.

The high incidence of uncertain diagnosis of coronary artery disease, mainly acute myocardial infarction, distorts the importance of the disease in the population, affecting health statistics and the evaluation of the requirements for prevention, treatment, and control of the disease. Considering the increasing importance of coronary artery disease as a cardiovascular cause of death in our country, it is paramount to know and disclose the bases that orient the statistics usually used to provide information about trends or other population approaches. In this study, the frequencies of medical care preceding death due to coronary artery diseases in the Brazilian regions and selected capitals were estimated, and the trends in those frequencies in Brazil in the 1980-1999 period are reported. 


\section{Methods}

A study of the temporal trends represented by quinquennial cut-points of mortality due to coronary artery diseases in Brazil in the 1980-1999 period was carried out. The latter year was used as the cross-sectional cut point for mortality due to the same cause in Brazilian macro-regions and in specific capitals of each region, as follows: the city of Belém (northern region); the cities of Recife and Salvador (northeastern region); the cities of Vitória, Belo Horizonte, and São Paulo (southeast); the city of Goiânia (west central region); and the cities of Florianópolis and Porto Alegre (southern region). DATASUS, the databank of the Health Ministry/FUNASA/ CENEPI, and the databank of the information system on mortality (Sistema de Informações sobre Mortalidade - SIM) were used to collect data from the years 1980,1985, 1990, and from 1995 to 1999 for Brazil, and 1999 for the regions and capitals. The following variables were analyzed: total number of deaths due to coronary artery disease (ICD 9th review $=410-414$, and 10 th review $=I 20-\mathrm{I} 25), \mathrm{CAD}$ specified as acute myocardial infarction (ICD 9th review $=410$, and 10th review $=\mathrm{I} 21, \mathrm{I} 22)$, or "other" coronary artery diseases (other CAD, theremaining ICD 9 th review $=411-414$, and 10 th review $=I 20$, I23-I25), ages above 20 years, sex, and medical care preceding death. Those variables were categorized as follows: with medical care (w-MC), without medical care (n-MC), and ignored medical care or with no information (ig-MC). Because of the change from the 9th to the 10th International Classification of Diseases (ICD) of the World Health Organization from 1996 onwards, the codes of the 2 ICD were made compatible and, for demonstration, the intermediate years codified by the 10th review (from 1996 to 1998) were included, aiming at preventing interpretation bias if only the last year of the series was considered.

In the descriptive analyses, the predominant approach was that for acute myocardial infarction, because it was the major representative of coronary artery diseases in the death statistics. Differences and increases or decreases in the frequencies of death preceded by medical care as compared with those without medical care or ignored medical care were included, as were the $t$ test for means, the test of difference between 2 proportions, and the ratios of frequencies (RF). For the dynamics of increase or decrease in deaths in each category of medical care, the calculations for each period or year were performed in relation to the immediately preceding one.

\section{Results}

Of the 76,310 deaths due to coronary artery disease in $1999,57,654(75.6 \%)$ were due to acute myocardial infarction, $59.5 \%$ occurring in males. Deaths in males and in females under the age of 60 years represented $13.5 \%$ and $11.0 \%$, respectively $(\mathrm{P}<0.01)$. Of the total number of deaths, medical care preceded death in $50.7 \%$, medical care did not occur in $8.2 \%$, and information about medical care preceding death was ignored or no record about it existed in the remaining $41.1 \%$.
The frequencies of death due to acute myocardial infarction preceded by medical care were greater among females in all age groups, with statistically significant differences $(\mathrm{P}<0.01$ to $\mathrm{P}<0.0001$ ), depending on the age group (tab. I). The ratios of frequency between deaths preceded by medical care and those with ignored medical care were $<1$ for males up to 50-59 years old, and did not exceed 1.2 in the remaining age groups; for females, on the other hand, they were greater than 1 , and increased up to 1.8 in the age group above 80 years. The percentage differences in the diverse frequencies between the sexes ranged from $+7.8 \%$ (70-79 years) to $+18.9 \%$ (20-29 years). The mean age among females was greater than that among males, both for deaths preceded by medical care and those in the other categories $(\mathrm{P}<0.0001)$. In an intragroup comparison of ages, males and females receiving medical care had a greater mean age than those not receiving it $(\mathrm{P}<0.0001$ for both cases $)$ (tab. I).

The frequencies of death for the total number of coronary artery diseases, considering the medical care reported on death certificates (fig. 1), and for acute myocardial infarction (fig. 2) are similar, slightly more elevated for deaths preceded by medical care for total coronary artery diseases, greater in the southern region for coronary artery disease and acute myocardial infarction, and lower in the northeastern region. In all regions, in the capitals and in the states, the frequencies of death preceded by ignored medical care are very high (ranging from $32 \%$ in the southern region to $46 \%$ in the northeastern region for coronary artery diseases and acute myocardial infarction) (figs. 1 and 2).

Of the capitals selected, the cities of Goiânia and Porto Alegre stand out with the greatest percentages of deaths preceded by medical care for acute myocardial infarction (fig.3) and total of coronary artery diseases (fig. 4), followed by the cities of Belo Horizonte and Salvador. The high frequencies of deaths with ignored medical care in the city of São Paulo (47.2\% for coronary artery diseases and $46.4 \%$ for acute myocardial infarction) have only been exceeded by those in the city of Belém (figs. 3 and 4).

Frequencies of death preceded by medical care for acute myocardial infarction in the regions (tab. II) were greater for females $(\mathrm{P}<0.05$ to $\mathrm{P}<0.001)$, the greatest being detected in the southeastern and southern regions and the lowest in the northeastern region. The frequencies of death with ignored medical care ranged from $36 \%$ (south) to $48.8 \%$ (southeast) for males, and from $27.3 \%$ (south) to $43.8 \%$ (northeast) for females. The ratio of frequency between deaths with medical care and those with ignored medical care was 1.5 for females in the country, the lowest being observed in the northeastern region, where no difference was found $(\mathrm{RF}=1)$. For males, the greatest ratio was observed in the southern region (1.4), the remaining regions showing low ratios.

For acute myocardial infarction and other coronary artery diseases, the frequencies of death with medical care showed an initial increase, then a decrease, and they returned to plateaus lower than those of 1980 at the end of the series, with a positive balance of $29 \%$ for acute myocardial infarction and a negative balance of $4.1 \%$ for other coronary artery diseases (tab. III-a, columns a). The increase was 


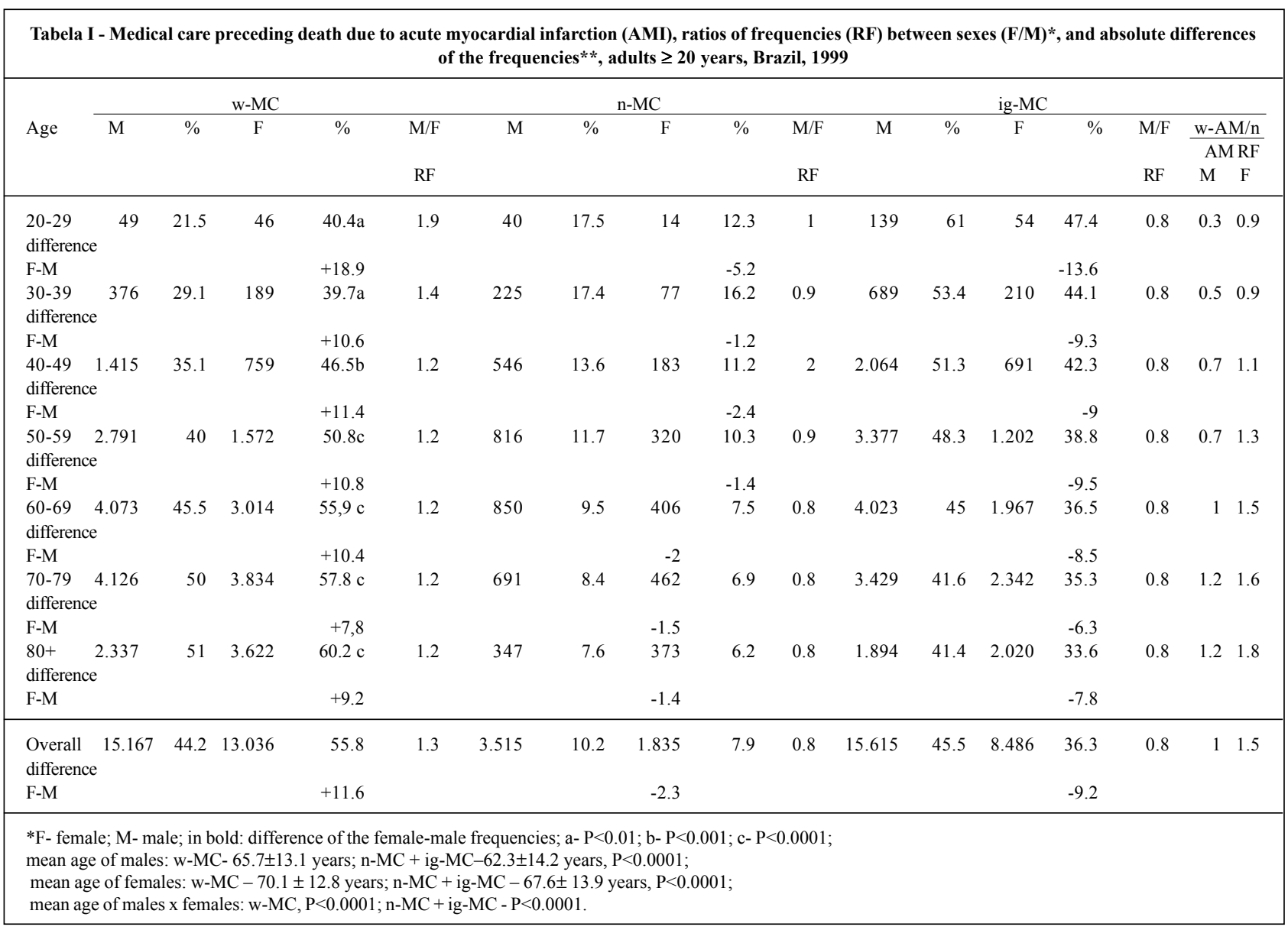

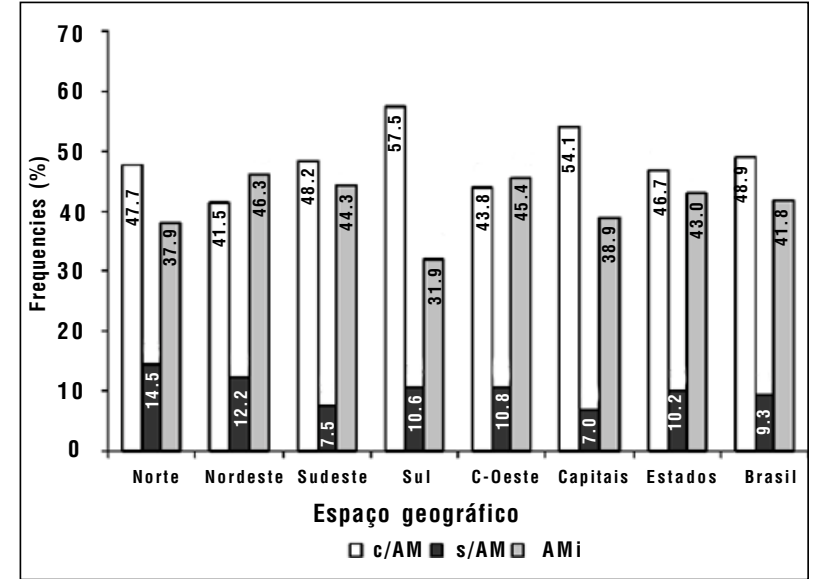

Fig. 1 - Medical care preceding death due to coronary artery diseases, Brazilian regions, states, and capitals, 1999.

greater for deaths with ignored medical care, being $+85 \%$ for acute myocardial infarction and $+96.4 \%$ for the remaining coronary artery diseases. Ignored medical care/with medical care final ratios of frequency of 2.9 and 92.3 were respectively observed for acute myocardial infarction and the remaining coronary artery diseases (figs. 5a, data by quinquennia, and 5b for consecutive years from 1996 to 1999, where a marked change may be detected in 1999). In the b columns of the same table, both acute myocardial infarction and the remaining coronary artery diseases show a negative balance for the frequencies of death with medical care and a positive balance for the 2 other categories, more expressive for the remaining coronary artery diseases. Figure 6a shows a summary of data behavior in the period, and table III-b and figure $6 \mathrm{~b}$ synthesize the stratification of deaths by categories of medical care during 20 years (tabs. III-a, III-b) (figs. 5a, 5b, and 6a, 6b).

\section{Discussion}

Coronary artery disease is one of the most important adult diseases in Brazil and one of those that, in the last decades, has benefited most from the technological advances for diagnosis and treatment and from the implementation of specialized intensive care units with monitoring currently spread throughout the country. These advances, availability, and comprehensiveness have not reached all social levels in the different regions. The absolute increase in the number of deaths due to acute myocardial infarction and other coronary artery diseases has been accompanied by an unequal increase in the medical care categories; 2.9 times more deaths occurred with ignored medical care compared with those with medical care for acute myocardial infarction; however, the other coronary artery diseases experienced a 


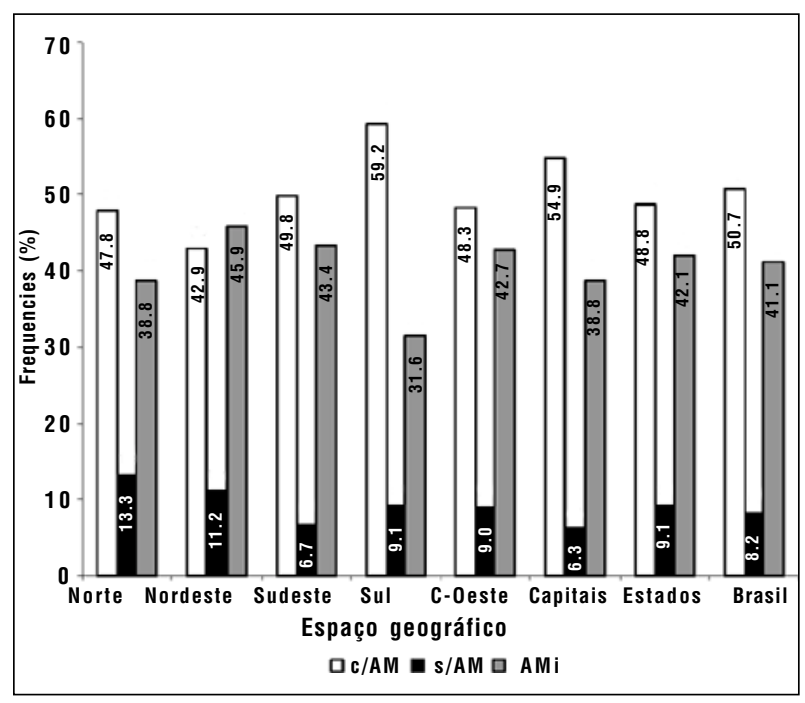

Fig. 2 - Medical care preceding death due to acute myocardial infarction, Brazilian regions, states, and capitals, 1999.

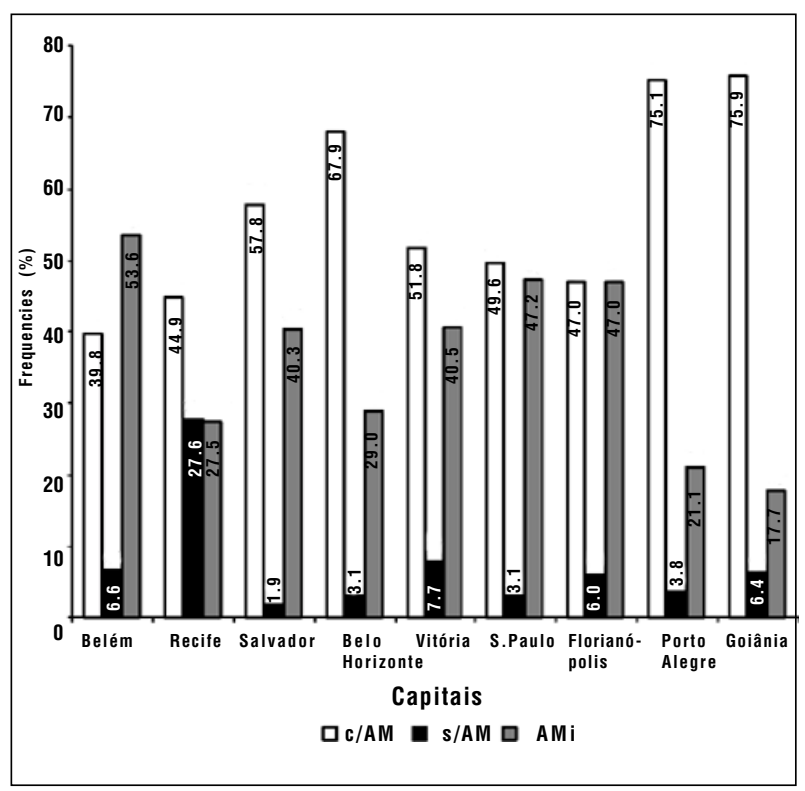

Fig. 3 - Medical care preceding death due to total coronary artery diseases, selected capitals, Brazil, 1999

decrease in deaths with medical care in specific temporal cut points. The trend points to difficulties in access to diagnosis and treatment for coronary artery diseases by $70 \%$ of the Brazilian population covered by the Brazilian public health system (Sistema Único de Saúde - SUS), unlike that provided by other health-care sources. Manifestations of the acute form of the disease, mainly acute myocardial infarction (approximately 75 to $85 \%$ of the cases), contribute to that because they do not always allow access to health care, diagnosis, and immediate therapeutic decisions required for each case. Consequently, many deaths actually occur with no medical care and hospitalization, making it impossible to discriminate, based on solid statistics, whe-

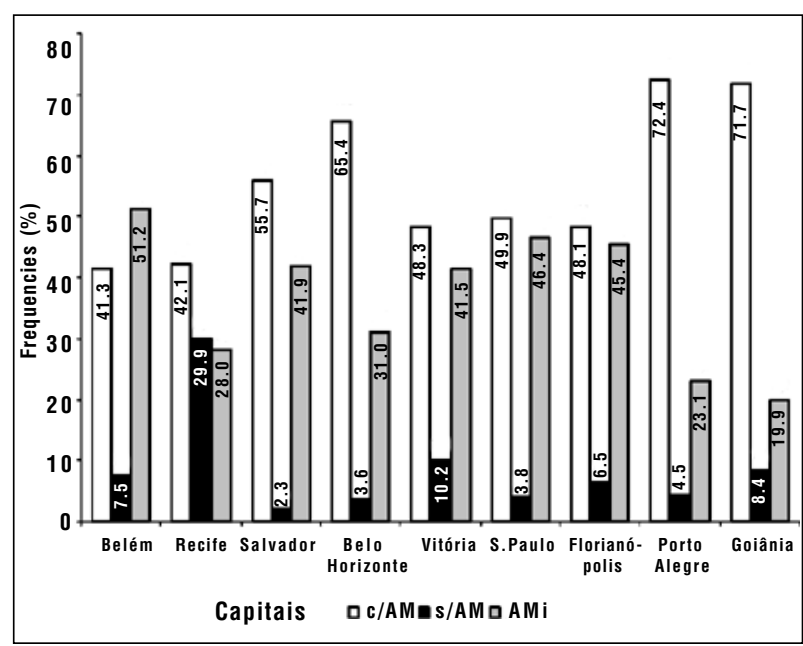

Fig. 4 - Medical care preceding death due to acute myocardial infarction, selected capitals, Brazil, 1999.

ther the deaths were sudden, instantaneous, or occurred with no time for medical care, or whether other reasons for the lack of medical care existed. Acute myocardial infarction is a frequent event and the major cause of sudden death, independently of the temporal criterion for this type of outcome. Therefore, acute myocardial infarction is the diagnosis of choice for filling out the death certificate for sudden death in general, as it is in other countries ${ }^{6,8}$. Diagnosis without confirmation is common in the elderly ${ }^{11}$, for whom validation studies have shown an excess of acute myocardial infarction of up to $20 \%{ }^{2}$, but global overestimates of diagnosis may reach up to $25 \%{ }^{6,8,13,14}$.

The field on the death certificate reserved for indicating the type of medical care may have been left blank due to doubt, fear, or uncertainty in regard to the accuracy of the cause of death reported. The results of this study showed high ratios of frequency when comparing deaths with ignored medical care due to acute myocardial infarction with those due to other coronary artery diseases in the 19801999 period (tab. III-a).

Sudden deaths due to coronary artery disease in young people were more often in the male sex ${ }^{19,23}$; deaths with ignored medical care predominated in males $<40$ years, but the percentage referring to sudden deaths could not be determined.

The predominance of deaths with medical care in females may reflect less aggressive initial symptoms, with better chances of access to medical services, but with later in-hospital worsening. Among males, sudden deaths are early, frequent, and more than $70 \%$ occur out of the hospital ${ }^{5,12,23,25}$, where, selectively, those assisted would have a better prognosis and the females the worst prognosis. Official data on hospitalizations via SUS in Brazil in the year 1999 show an in-hospital lethality due to acute myocardial infarction for males of $14.2 \%$ and for females of $19.9 \%$, with shorter hospitalization for the latter. For the other coronary artery diseases, the values were the same, $2.9 \%$ for each sex, with shorter hospitalization also for females. For females with acute myocardial infarction, the 


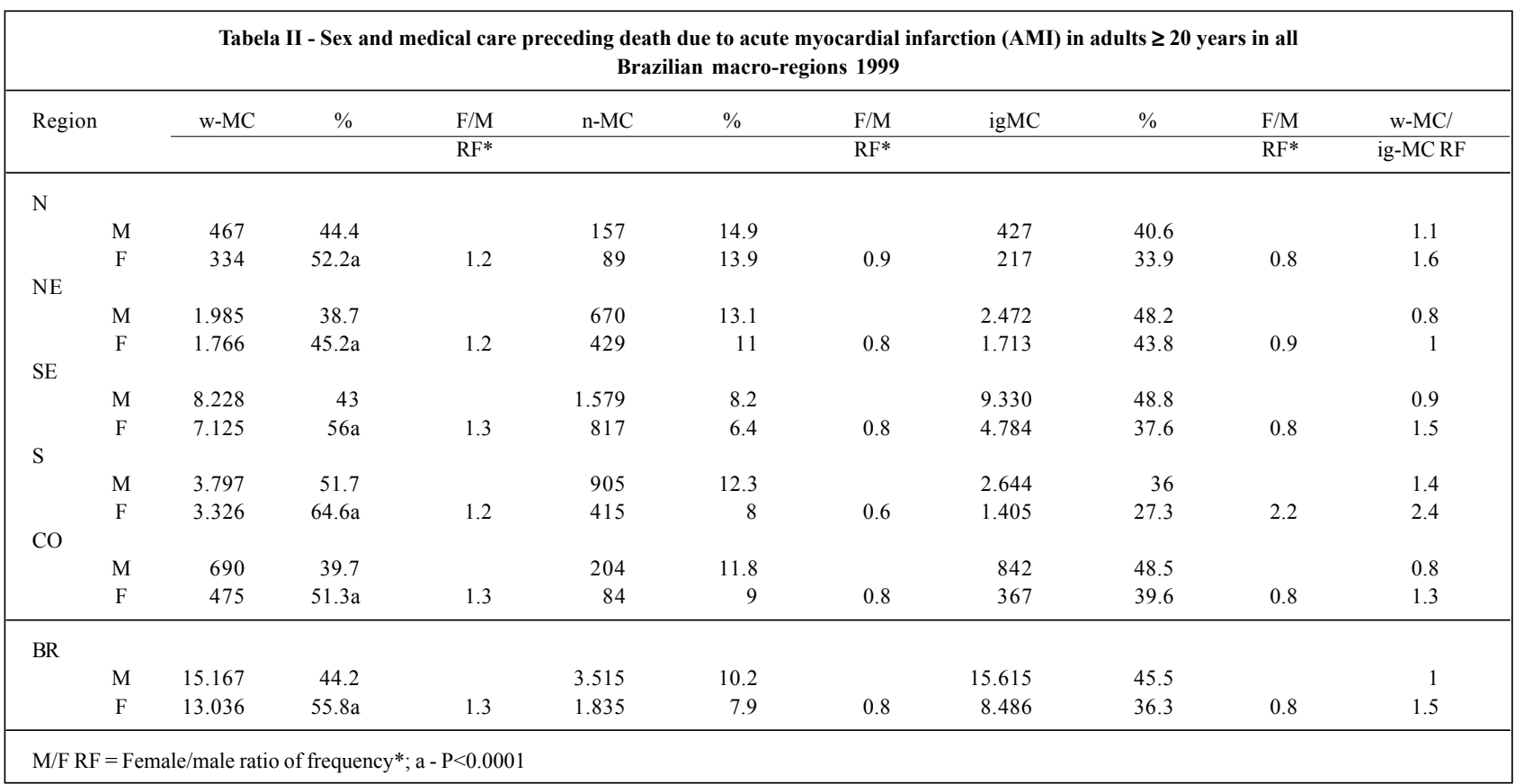

\begin{tabular}{|c|c|c|c|c|c|c|c|c|c|c|c|c|c|c|c|c|c|c|}
\hline \multirow{3}{*}{ Year } & \multicolumn{9}{|c|}{ Acute myocardial infarction } & \multicolumn{9}{|c|}{ Other coronary artery diseases } \\
\hline & \multirow[t]{2}{*}{$\mathrm{w}-\mathrm{MC}$} & \multicolumn{2}{|c|}{$\%$ of I or R } & \multirow[t]{2}{*}{ n-MC } & \multicolumn{2}{|c|}{$\%$ of I or R } & \multirow[t]{2}{*}{ ig-MC } & \multicolumn{2}{|c|}{$\%$ of I or R } & \multirow[t]{2}{*}{ n-MC } & \multicolumn{2}{|c|}{$\%$ of I or R } & \multirow[t]{2}{*}{ w-MC } & \multicolumn{2}{|c|}{$\%$ of I or R } & \multirow[t]{2}{*}{ ig-MC } & \multicolumn{2}{|c|}{$\%$ of I or R } \\
\hline & & $\mathrm{a}$ & $\mathrm{b}$ & & $\mathrm{a}$ & $\mathrm{b}$ & & $\mathrm{a}$ & $\mathrm{b}$ & & $\mathrm{a}$ & $\mathrm{b}$ & & $\mathrm{a}$ & $\mathrm{b}$ & & $\mathrm{a}$ & $\mathrm{b}$ \\
\hline \multirow[t]{2}{*}{1980} & 22.067 & & & 3.256 & & & 11.653 & & & 11.199 & & & 596 & & & 3.985 & & \\
\hline & 59.7 & & & 8.8 & & & 31.5 & & & 71 & & & 3.8 & & & 25.3 & & \\
\hline \multirow[t]{2}{*}{1985} & 27.847 & 26.2 & & 4.292 & 10.2 & & 12.084 & 3.7 & & 13.212 & 17.8 & & 350 & -37.5 & & 3.748 & -6 & \\
\hline & 63 & & 5.5 & 9.7 & & 10.2 & 27.3 & & -13.3 & 76.3 & & 7.5 & 2 & & -46.8 & 21.7 & & -14.4 \\
\hline \multirow[t]{2}{*}{1990} & 31.098 & 11.7 & & 5.110 & 19 & & 13.533 & 12 & & 12.022 & -9 & & 808 & 130.9 & & 3.548 & -5.3 & \\
\hline & 62.5 & & -0.7 & 10.27 & & 5.9 & 27.2 & & -0.4 & 73.4 & & -3.8 & 4.9 & & 144 & 21.7 & & 0.1 \\
\hline \multirow[t]{2}{*}{1995} & 32.092 & 3.2 & & 5.839 & 14.3 & & 15.809 & 16.8 & & 11.200 & -6.8 & & 1.172 & 45 & & 3.430 & -3.3 & \\
\hline & 59.7 & & -4.5 & 10.9 & & 5.8 & 29.4 & & 8.1 & 70.9 & & -3.4 & 7.4 & & 50.3 & 21.7 & & 0.2 \\
\hline \multirow[t]{2}{*}{1999} & 28.203 & -12.1 & & 5.350 & -8.4 & & 24.101 & 52.5 & & 10.520 & -6.1 & & 897 & -23.5 & & 7.239 & 111 & \\
\hline & 48.9 & & -18.1 & 9.3 & & -14.4 & 41.8 & & 42.1 & 56.4 & & -20.4 & 4.8 & & -35.3 & 38.8 & & 78.8 \\
\hline $\begin{array}{l}1999- \\
1980\end{array}$ & & 29 & -17.8 & & 35.1 & 7.4 & & 85 & 36.5 & & -4.1 & -20.2 & & 114.9 & 112.3 & & 96.4 & 64.6 \\
\hline $\begin{array}{l}\text { a) per } \\
\text { freque } \\
\text { a: AM } \\
=10.4\end{array}$ & $\begin{array}{l}\text { ntage of } \\
\text { les of dec } \\
\text { g-MC/w } \\
\text { or CAD }\end{array}$ & acrease & r red & w-MC & $\begin{array}{l}\text { numbe } \\
\text { tard to } \\
\text { 2. For } \\
\text { ww-Mc }\end{array}$ & $\begin{array}{l}\text { er of de } \\
\text { the tota } \\
\text { CAD: i } \\
\text { C=92.1 }\end{array}$ & $\begin{array}{l}\text { for each } \\
\mathrm{mber} \text { of d } \\
\text { IC/w-MC } \\
\text { MI: ig-M }\end{array}$ & 92.3 & n-MC/ & $\begin{array}{l}\text { lponent } \\
\mathrm{MC}=1\end{array}$ & $\kappa \Gamma$ & totals & other & AMI: & $\begin{array}{l}\mathrm{C} \text { of } 1 \mathrm{r} \\
\mathrm{MC} \text { year; }\end{array}$ & {$[\mathrm{C}=18$} & $\begin{array}{l}\text { duction } \\
\text { tals in ce } \\
\mathrm{n}-\mathrm{MC} / \mathrm{y} \\
=110.8\end{array}$ & $\begin{array}{l}\text { in the } \\
\text { olumn } \\
\text { W-MC }\end{array}$ \\
\hline
\end{tabular}

temporal reference for medical care obtainment is $6 \%$ to $7 \%$ in the first 5 minutes of symptoms as compared with $2 \%$ to $6 \%$ for males ${ }^{26}$, which partially supports the chance that the possibilities discussed are true. In addition, similar information may be found in the literature ${ }^{27-29}$, as may be the reference about loss of records of nonfatal events for females ${ }^{30}$, perhaps indicating an unreal increase in lethality.

In the temporal cut points of the historical series, the frequencies of death with medical care due to other coronary artery diseases were always greater than those due to acute myocardial infarction $(\mathrm{P}<0.01$ to $\mathrm{P}<0.0001)$. The sudden increase in deaths with ignored medical care due to other coronary artery diseases in 1999 may be an artifact of the databank, because a drop in the absolute number of deaths in that year was observed, as were marked changes in the distribution of deaths by the category of acute myocardial infarction occurring in 1999.

Considering the lack of information about previous medical care for half of the deaths attributed to acute myocardial infarction and for $38.8 \%$ of those attributed to other coronary artery diseases in Brazil, another possibility could be the misuse of the ICD rules by the teams codifying the deaths, mainly when the physician or the individual responsible for the diagnosis did not properly clarify the basic cause of death. Only the cities of Porto Alegre and Goiânia had high percentages of deaths with medical care without 


\begin{tabular}{|c|c|c|c|c|c|c|}
\hline \multicolumn{7}{|c|}{$\begin{array}{l}\text { Tabela III.b - Increase or reduction in the number of deaths and } \\
\text { respective percentages, acute myocardial infarction (AMI) and other } \\
\text { coronary artery diseases by category of medical care in successive } \\
\text { quinquennia, Brazil } 1980 \text { - } 1999\end{array}$} \\
\hline Medical care & AMI & $\%$ & Other DAC & $\%$ & Total & $\%$ \\
\hline w-MC & 6.136 & 29.7 & -679 & -23.6 & 5.457 & 23.2 \\
\hline $\mathrm{n}-\mathrm{MC}$ & 2.094 & 10.1 & 301 & 10.5 & 2.395 & 10.2 \\
\hline ig-MC & 12.448 & 60.2 & 3.254 & 113.1 & 15.702 & 66.6 \\
\hline Total & 20.678 & 100 & 2.876 & 100 & 23.554 & 100 \\
\hline
\end{tabular}

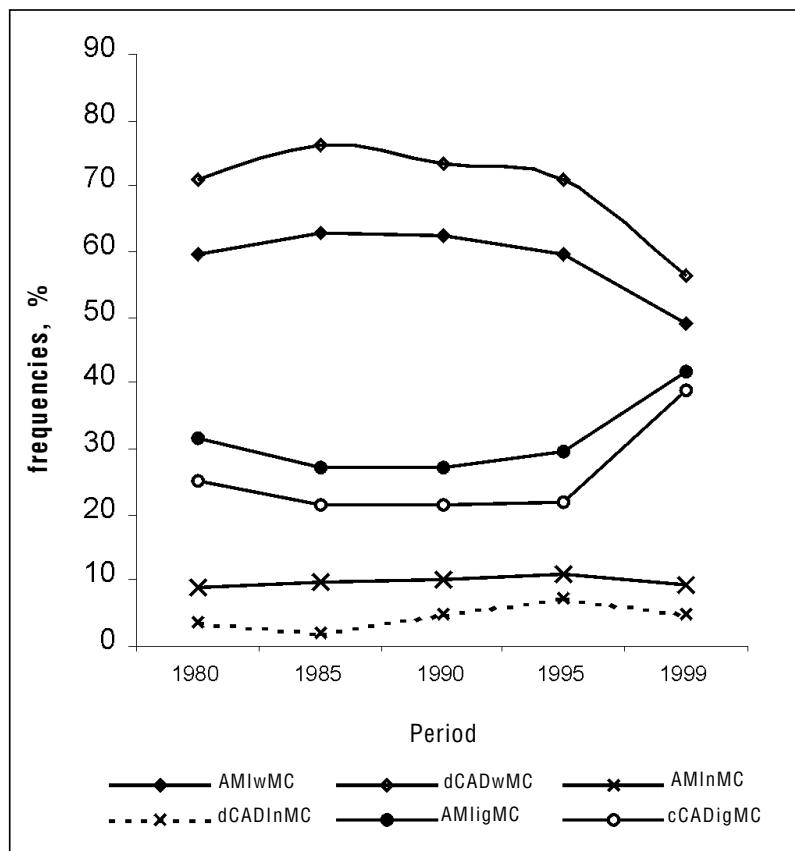

Fig. 5a - Trends in medical care preceding death due to acute myocardial infarction and other coronary artery diseases, Brazil, 1980-1999.

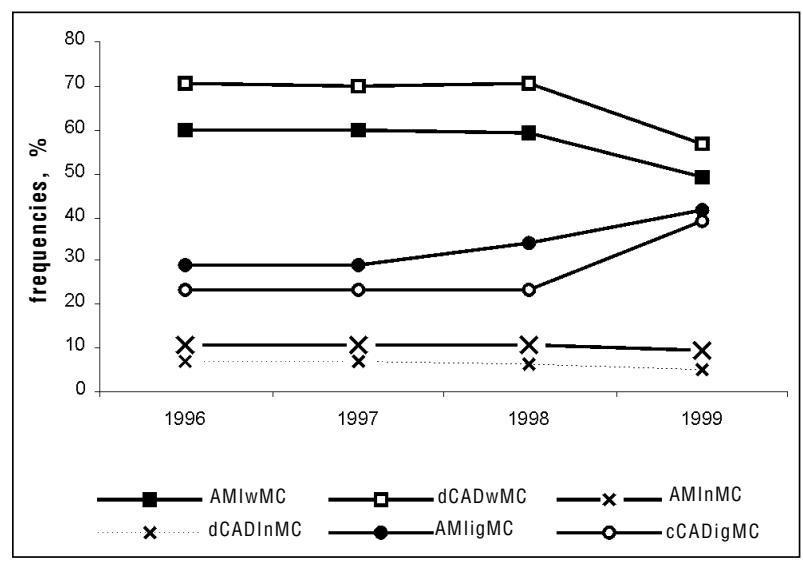

Fig. $5 b$ - Trends in medical care preceding death due to acute myocardial infarction and other coronary artery diseases, Brazil, 1996-1999.

significant differences between acute myocardial infarction and other coronary artery diseases.

The discrepancies between the statistics in the regions and capitals, better in the southern region and worse in the northeastern region, are surprising because of the si-

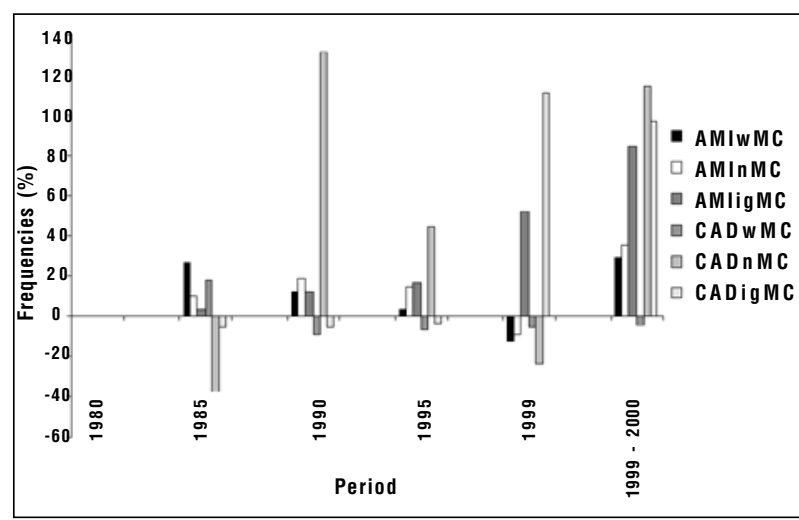

Fig. 6a - Dynamics of medical care preceding death due to acute myocardial infarction and other coronary artery diseases, Brazil, 1980-1999.

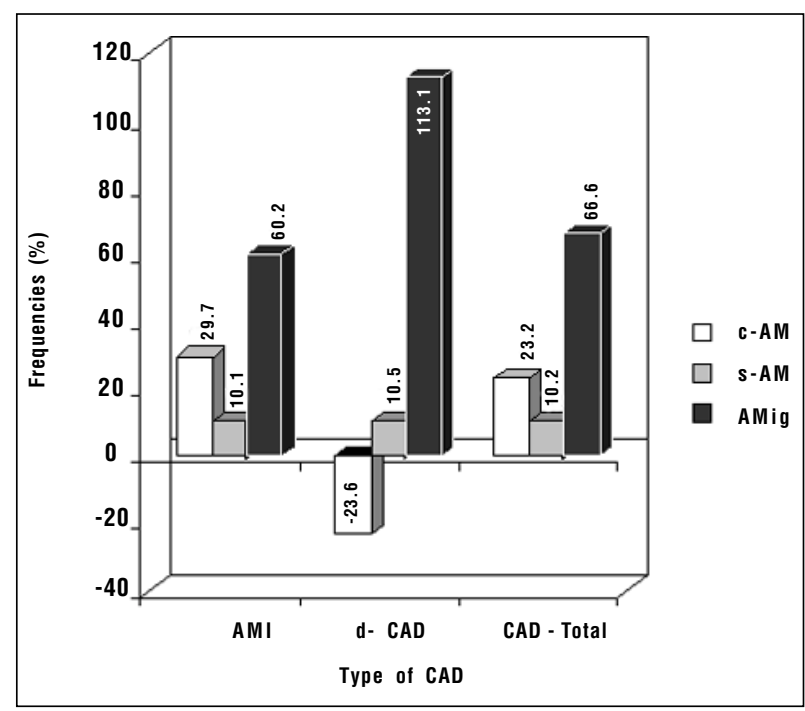

Fig. $6 \mathrm{~b}$ - Increase or decrease in the total number of deaths due to acute myocardial infarction or other coronary artery diseases, successive quinquennia, 1980-1999.

milarity between the northern and southeastern regions for acute myocardial infarction. In the latter, the greatest disadvantage occurred for death with ignored medical care. The Brazilian regions comprise heterogeneous states with repercussions ranging from the access to emergency services to the quality of health statistics. However, data from the capitals showed that, despite the greater development and region of insertion, in the city of São Paulo, coronary artery diseases have been the major cause of death for many years, but the statistics there were poor, the same occurring in the city of Florianópolis, where coronary artery diseases have been the major cause of death for a short time.

With $50 \%$ of the diagnoses reported as "suspect" in regard to accuracy, it is somehow necessary to clarify the magnitude of the overestimate of coronary artery diseases on death certificates, but, as in other countries, minor chances of underestimation represented by deaths codified in the group of the ill-defined causes also exist ${ }^{7,8}$. Validation of the diagnoses of coronary artery disease on death certificates is one of the activities performed by epidemiological 
surveillance programs in industrialized countries. This type of procedure is essential to national data, so the position of coronary artery diseases in the death statistics in Brazil can be more reliably obtained. Usually, surveillance routinely uses methodology with descriptive analysis ${ }^{31}$, which may facilitate its diffusion throughout the country. However, independently of the initial validation, monitoring information about medical care in deaths due to cardiovascular diseases that can result in sudden death is required. Criteria for the diagnosis of acute myocardial infarction and other coronary artery diseases should be elaborated and spread out, when medical care is not possible or is not available, or when no autopsy service is available; however, international criteria that can be adapted and tested in Brazil already exist.

Considering that the quality of the statistics about mortality is paramount for epidemiological research, because they portray population features, it is recommended that, in studies performed in Brazil with statistics available for coronary artery diseases, the quality of the databank information and the possible resulting mistakes be assessed.

\section{References}

1. Center of Disease Control-CDC. State-specific mortality from sudden cardiac death-United States, 1999. MMWR Morb Mort Wkly Rep 2002; 15:123-6.

2. Zehng J, Croft JB, giles WH, Mensah GA. Sudden cardiac death in the United States, 1989-1998. Circulation 2001;104:2158-63.

3. Virmani R, Buk AP, Farb A . Sudden cardiac death. Cardiovasc. Pathol 2001; 10:211-8.

4. Goraya TY, Jacobsen SJ, Belau PG, Weston SA, Kottke TE, Roger VL. Validation of death certificate diagnosis of out-of-hospital coronary heart disease deaths in Olmsted County, Minnesota. Mayo Clin Proc 2000; 75: 681-7.

5. Holmberg M, Holmberg S, Herlitz J. The problem of out-of-hospital cardiac-arrest prevalence of sudden death in Europe today.Am JCardiol 1999; 83 (5B): 88D-90D.

6. Lloyd-Jones DM, Martin DO, Larson MG, Levy D. Accuracy of death certificates for coding coronary heart disease as the cause of death. Ann Intern Med 1998; 129: 1020-6.

7. Gillum RF. Sudden cardiac death in Hispanic American and African American Am J Public Health 1997; 87: 1461-6.

8. Armstrong DL, Wing SB, Tyroler HA. Race differences in estimates of sudden coronary heart disease mortality, 1980-1988: the impact of ill-defined death. Int J Epidemiol 1995; 24: 255-7.

9. Coady SA, Sorlie PD, Cooper LS, Folsom AR, Rosamond WD, Conwill DE. Validation of death certificate diagnoses for coronary heart disease: the Atherosclerosis Risk In Communities (ARIC) study. J Clin Epidemiol 2001; 54: 40-50.

10. Burnand B, Feinstein AR. The role of diagnostic in consistency in changing rates of occurrence for coronary heart disease. J Clin Epidemiol 1992; 45: 929-40.

11. The United Kingdom Heart Attack Study (UKHAS) collaborative Group. The falling mortality from coronary heart disease: a clinicopathological perspective. The United Kingdom Heart Attack Study (UKHAS) collaborative Group. Heart 1998; 80:121-6.

12. Iribarren C, Crow RS, Hannan PJ, Jacobs DR Jr, Lepker RV. Validity os death certificates diagnosis of out-of hospital sudden death. Am J Cardiol 1998; 82:50-3

13. Every NR, Parsons L, Hlatky MA, et al. Use and accuracy of state death certificates for classification of sudden cardiac deaths in high-risk populations. Am Heart J 1997; 134: 1129-32.

14. Edda Ambach, Walter Rabl, Christoph Unger, Gunter Weiss. The Inadequacy of death certificates claiming myocardiol infarction without autopsy verification (Letter). Forensic Sci Int 1995; 71: 75-6.

15. Kircher T, Nelson J, Burdo H. The autopsy as a measure of accuracy of the death certificate. N Engl J Med 1985; 313: 1263-9.

16. Jackson R, Graham P, Beaglehole R, De Boer G. Validation of coronary heart disease death certificate diagnoses. NZ Med J 1988; 101: 658-60.

17. Morentin B, Paz Suarez-Mier M, Audicana C, Aguilera B, Garamendi MP. Inci- dencia y causas de muerte subita en personas abajo de los 36 años. Med Clin (Barc) 2001; 116: 281-5.

18. Wren C, O'Sullivan JJ, Wright C. Sudden Cardiac death in children and adolescents. Heart 2000; 83:410-3.

19. Thomas AC, Knapman PA, Krikler DM, Davies MJ. Community study of the causes of "natural" sudden death. BMJ 1988; 297: 1453-6.

20. DroryY,TuretzY,Hiss Y,LevB, FismanEZ, PinesA, KramerMR. Suddenunexpected death in persons less than 40 years of age. Am J Cardiol 1991; 68: 1388-92.

21. Oalmann MC, Palmer RW, Guzman MA, Strong JP. Sudden death, coronary heart disease, atherosclerosis and myocardial lesions in young men. Am J Epidemiol 1980; 112: 639-49.

22. Corrado D, Thiene G, Pannelli N. Sudden death as the first manifestation of coronary artery disease in young people (less than or equal to 35 years). Eur Heart J 1998; (Suppl N): 239-44

23. Fornes P, Lecomte D, Nicolas G. Sudden out-of-hospital coronary death in patients with no previous cardiac history: an analysis of 221 patients studied at autopsy. J Forensic Sci 1993; 38: 1084-91.

24. Lessa I.Perfil das Doenças Cardiovasculares no Brasil. In:Mion Jr D \& Nobre F. Risco Cardiovascular Global, 1 ${ }^{a}$ Ed, Lemos Editorial, São Paulo, pág. 15-29.

25. Manfredini R, Portaluppi F, Grandi E, Fersini C, Gallerani M. Out-of-hospital sudden death referring to an emergency department. J Clin Epidemiol 1996; 49 : 865-8.

26. Ferrières J, Arveiler D, Amouyel P, et al. Epidemiologie de la mort subite par le maladie coronaire du coeur en France, 1985-1992. Arch Mal Coeur Vaiss 1997; 90:483-7

27. Vaccarino V,Krumholz HM, Yarzebski J, Gore JM, Goldberg RJ. Sex differences in 2-year mortality after hospital discharge for myocardial infarction. Ann Intern Med 2001;134: 173-81

28. Sonke GS, Beaglehole R, StewartAW, Jackson R, Stewart FM. Sex differences in case fatality before and after admission to hospital after acute cardiac events: analysis of community based coronary heart disease. BMJ 1996; 313: 853-5

29. Tuntall-Pedoe H, Kuuwasmaa K, Amouyel P, Arveiler D, Rajakangas AM, Pajak a myocardial infarct and coronary heart death in the World Health Organization MONICA Project. Registration, procedures events, rates, and case fatality rates in 38 populations from 21 countries in four continents. Circulation 1994; 9:583-612.

30. Lowel H, Dobson A, Keil U, et al. Coronary heart disease case fatality in four countries: a community study. The Acute Myocardial Infarction Register Teams of Auckland, Ausburg, Bremen, FINMONICA, Newcastle, and Perth. Circulation 1993; 88:2524-31.

31. Buehler JW. Surveillance. In Rothman KJ, Greenland S Modern Epidemiology, $2^{\text {nd }}$. ed, Philadelphia, Lippincott-Raven Publishers 1998; 435-57. 